\title{
UMA ANÁLISE DA INSERÇÃO DA TEMÁTICA ÉTNICA E RACIAL NOS \\ COMPONENTES CURRICULARES NAS INSTITUIÇÕES PÚBLICAS DE NÍVEL SUPERIOR DOS ESTADOS DE ALAGOAS E SERGIPE
}

\author{
Victor Araujo dos Anjos ${ }^{1}$; Edna Maria de Araújo ${ }^{2}$ \\ 1. Bolsista PIBIC/CNPq, Graduando em Medicina, Universidade Estadual de Feira de Santana, e-mail: \\ victoraraujo_fsa@hotmail.com \\ 2. Orientador, Departamento de Saúde, Universidade Estadual de Feira de Santana, e-mail: \\ ednaaraujo@uefs.br
}

PALAVRAS-CHAVE: Política de Saúde; Componentes curriculares; Instituições públicas; Temática étnica e racial.

\section{INTRODUÇÃO}

O Ministério da Saúde (MS), considerando as condições desfavoráveis de saúde da população negra, que constitui atualmente mais da metade da população do país, e visando tanto à eliminação das iniquidades quanto à redução dos agravos que incidem nas altas e desproporcionais taxas de morbidade e mortalidade neste grupo populacional, elaborou a Política Nacional de Saúde Integral da População Negra (PNSIPN) (BRASIL, 2008).

Dentro desse contexto, é notória a importância da implementação da temática étnica racial nas universidades públicas, justamente pela capacidade dessas instituições na disseminação de conhecimento e aumento da sua relevância nos meios de aprendizagem e formação acadêmica, tornando viável transformações que podem ser alcançadas na reorganização da atenção à saúde, através da adoção de ações institucionais globalizantes e includentes. Além disso, a desigualdade de raça é estruturante da desigualdade social brasileira e inúmeras são as evidências que apontam as barreiras à participação igualitária dos negros em diversos campos da vida social e para as consequências que estas desigualdades e discriminações produzem não apenas para os negros, mas para a sociedade como um todo. Dessa maneira, o racismo e o racismo institucional são práticas que colocam pessoas de grupos raciais ou étnicos em situação de desvantagem no acesso aos benefícios gerados pela ação das instituições e organizações, como, por exemplo, na morosidade da implementação de políticas públicas.

Diante disso, esse trabalho tem como objetivo "Analisar a inserção da temática étnica racial nos componentes curriculares em instituições de nível superior nos cursos de saúde dos estados de Sergipe e Alagoas no período de 2010 a 2016".

\section{MATERIAL E MÉTODOS OU METODOLOGIA (ou equivalente)}

Avaliação com abordagem quantitativa da implementação da política por meio da análise do indicador de ensino e pesquisa, contendo parâmetros, fontes, meios de verificação e premissas esperadas. As técnicas de coleta utilizadas foram a análise dos Projetos pedagógicos dos cursos de graduação de saúde (enfermagem, medicina, fisioterapia, nutrição, psicologia e odontologia) das universidades públicas de Sergipe e Alagoas.

\section{RESULTADOS E/OU DISCUSSÃO (ou Análise e Discussão dos Resultados)}

Dos cursos analisados no estado de Sergipe, não houve inclusão da temática étnica e racial nos componentes curriculares mesmo após, em 2009, o ano da efetivação da PNSIPN como lei. Por sua vez, em Alagoas dos sete cursos analisados, dois (28,6\% do total) tiveram a 
inclusão da temática étnica e racial nos componentes curriculares pedagógicos, são eles: o curso de Medicina e o de Psicologia da Universidade Federal de Alagoas.

A partir desta análise pode se observar que uma parcela insignificante das instituições públicas de ensino superior, dos estados de Sergipe e Alagoas, apresenta disciplinas na grade curricular que abrangem a abordagem étnico racial nos cursos de saúde. Dentro desse contexto, os temas explorados nos currículos de tais disciplinas tem o objetivo de discutir a influência da raça/cor enquanto constructo social como determinante das condições de saúde e de doença. É relevante destacar o curso de Medicina da Universidade Federal de Alagoas, que possui uma disciplina própria para a temática de saúde da população negra, em caráter eletivo, intitulada: "Saúde das populações: População Negra".

Dentro de contexto, podemos ressaltar o pensamento reforçado por Freitas et al. (2013) de que "o reconhecimento do racismo institucional e da falta de análises mais profundas acerca das iniquidades entre brancos e não brancos ainda não tem resultado em mudanças de comportamento e olhares no âmbito das academias. Para alguns autores, perpetua-se um preconceito sutil e insidioso, que dá força à invisibilidade das comunidades negras e quilombolas frente às instituições."

Tabela 1. Presença da temática étnica e racial nos componentes curriculares pedagógicos de instituições públicas do estado de Alagoas e Sergipe.

\begin{tabular}{llllllllll}
\multicolumn{1}{c}{ Instituições } & \multicolumn{7}{c}{ Cursos } \\
\cline { 2 - 9 } & $\mathbf{1}$ & $\mathbf{2}$ & $\mathbf{3}$ & $\mathbf{4}$ & $\mathbf{5}$ & $\mathbf{6}$ & $\mathbf{7}$ & $\mathbf{8}$ \\
\hline Universidade Federal de Sergipe & - & - & - & - & - & - & - & - \\
Universidade Federal de Alagoas & - & - & - & + & + & - & - & - \\
Universidade Estadual de Alagoas & - & - & - & - & - & - & - & - \\
Universidade Estadual de Ciências da Saúde & - & - & - & - & - & - & - & - \\
de Alagoas & & & & & & & &
\end{tabular}

Legenda: 1.Enfermagem 2.Nutrição 3.Fisioterapia 4.Psicologia 5.Medicina 6. Odontologia.

$(+)=$ presente; $(-)=$ ausente.

\section{CONSIDERAÇÕES FINAIS (ou Conclusão)}

Para que a PNSIPN seja definitivamente implementada é fundamental que a formação do profissional de saúde tenha também um enfoque na diversidade e especificidades sociais, econômicas e culturais dessa população negra e outras populações vulnerabilizadas. Pois só dessa maneira haverá melhoria nos indicadores de saúde destas populações e a possibilidade de alcance da equidade em saúde não somente nos estados pesquisados, como também em todo o território Brasileiro.

\section{REFERÊNCIAS}

FREITAS, Daniel Antunes et al . Percepção de estudantes da área da saúde sobre comunidades rurais quilombolas no norte de Minas Gerais-Brasil. Rev. CEFAC, São Paulo, v. 15, n. 4, p. 941-946, Aug. 2013 . Available from $<$ http://www.scielo.br/scielo.php?script=sci_arttext\&pid=S1516$18462013000400023 \& \operatorname{lng}=$ en\&nrm $=$ iso $>$. access on 07 jun. 2018. 
FREITAS, Daniel Antunes et al . Percepção de estudantes da área da saúde sobre comunidades rurais quilombolas no norte de Minas Gerais-Brasil. Rev. CEFAC, São Paulo , v. 15, n. 4, p. 941-946, Aug. 2013 . Available from $<$ http://www.scielo.br/scielo.php?script=sci_arttext\&pid=S1516-

$18462013000400023 \& \operatorname{lng}=$ en\&nrm=iso $>$. access on 07 Jun. 2018.

Brasil. Ministério da Saúde. Secretaria de Gestão Estratégica e Participativa. Departamento de Apoio à Gestão Participativa. Política Nacional de Saúde Integral da População Negra : uma política para o SUS / Ministério da Saúde, Secretaria de Gestão Estratégica e Participativa, Departamento de Apoio à Gestão Participativa. - 2. ed. - Brasília: Editora do Ministério da Saúde, 2013.

Brasil. Ministério da Saúde. Secretaria de Gestão Estratégica e Participativa. Departamento de Apoio à Gestão Participativa. Política Nacional de Saúde Integral da População Negra : uma política para o SUS / Ministério da Saúde, Secretaria de Gestão Estratégica e Participativa, Departamento de Apoio à Gestão Participativa. - Brasília: Editora do Ministério da Saúde, 2010.

POLÍTICA NACIONAL DE SAÚDE INTEGRAL DA POPULAÇÃO NEGRA: plano operativo. Brasília: Ministério da Saúde, 2008.

BRASIL. Ministério da Saúde (MS). Política Nacional de Saúde Integral da População Negra. Brasília: MS; 2007

SANTOS, Cibele Araujo Camargo Marques dos. Convergência temática entre produção científica e política nacional de pesquisa em saúde pública: estudo com base em análise de artigos de periódicos indexados. 2010. Tese (Doutorado em Cultura e Informação) - Escola de Comunicações e Artes, Universidade de São Paulo, São Paulo, 2010. doi:10.11606/T.27.2010.tde-07072010-103008. Acesso em: 2018-05-06.

SANTOS, Marco Antonio dos; VIEIRA, Ricardo Quintão; CAVERNI, Leila Maria Rissi. Saúde da população negra: estudo bibliométrico em artigos, teses e dissertações digitais nacionais. Revista ACB, [S.1.], v. 19, n. 1, p. 13-22, mar. 2014. ISSN 1414-0594. Disponível em: $<$ https://revista.acbsc.org.br/racb/article/view/935>. Acesso em: 06 maio. 2018.

MONTEIRO, Rosana Batista. Orientações e experiências para a implementação da Política Nacional de Saúde Integral da População Negra no âmbito da formação e Educação Permanente em Saúde. 2010 